\title{
Antimicrobial activity of actinomycetes and characterization of actinomycin-producing strain KRG-1 isolated from Karoo, South Africa
}

\author{
Ivana Charousová ${ }^{1,2 *}$, Juraj Medo ${ }^{2}$, Lukáš Hleba ${ }^{2}$, Miroslava Císarová $^{3}$, Soňa Javoreková ${ }^{2}$
}

${ }^{1}$ Apha medical s.r.o., Clinical Microbiology Laboratory, Slovak Republic, ${ }^{2}$ Slovak University of Agriculture in Nitra, Faculty of Biotechnology and Food Sciences, Department of Microbiology, Slovak Republic, ${ }^{3}$ University of SS. Cyril and Methodius in Trnava, Faculty of Natural Sciences, Department of Biology, Slovak Republic

\begin{abstract}
In the present study we reported the antimicrobial activity of actinomycetes isolated from aridic soil sample collected in Karoo, South Africa. Eighty-six actinomycete strains were isolated and purified, out of them thirty-four morphologically different strains were tested for antimicrobial activity. Among 35 isolates, $10(28.57 \%)$ showed both antibacterial and antifungal activity. The ethyl acetate extract of strain KRG-1 showed the strongest antimicrobial activity and therefore was selected for further investigation. The almost complete nucleotide sequence of the 16S rRNA gene as well as distinctive matrix-assisted laser desorption/ionization-time-of-flight/mass spectrometry (MALDI-TOF/MS) profile of whole-cell proteins acquired for strain KRG-1 led to the identification of Streptomyces antibioticus KRG-1 (GenBank accession number: KX827270). The ethyl acetate extract of KRG-1 was fractionated by HPLC method against the most suppressed bacterium Staphylococcus aureus (Newman). LC//MS analysis led to the identification of the active peak that exhibited UV-VIS maxima at $442 \mathrm{~nm}$ and the ESI-HRMS spectrum showing the prominent ion clusters for $\left[\mathrm{M}-\mathrm{H}_{2} \mathrm{O}+\mathrm{H}\right]^{+}$at $m / z 635.3109$ and for $[\mathrm{M}+\mathrm{Na}]^{+}$at $m / z$ 1269.6148. This information could be assigned to chromopeptide lactone antibiotic - actinomycin. Our results suggest that unexplored soils could be an interesting source for exploring antibacterial secondary metabolites.
\end{abstract}

Keywords: Actinomycin/antimicrobial activity. Streptomyces. Soil. 16S rRNA. MALDI-TOF MS.

\section{INTRODUCTION}

Actinomycetes are free living Gram - positive bacteria having high $\mathrm{G}+\mathrm{C}$ content $(>55 \%)$ in DNA (Kämpfer, 2012). The most important and dominant genus within Actinobacteria is Streptomyces (Ceylan, Okmen, Ugur, 2008). Members of this group referred to as the biological antagonistic types. They are of special interest since streptomycetes are the ones that are exploited and their metabolites are used in the manufacture of antibiotics (Kekuda, Shobha, Onkarappa, 2010). Streptomyces provides more than half $(70 \%)$ of the naturally occurring antibiotics (Bérdy, 2005) with high commercial value and continue to be routinely screened for interesting bioactive substances (Takahashi, 2004; Meena et al., 2013).

\footnotetext{
*Correspondence: I. Charousová. Department of Microbiology, Faculty of Biotechnology and Food Sciences, Slovak University of Agriculture in Nitra, Tr. A. Hlinku 2, 94976 Nitra, Slovak Republic. Tel. +421 37641 5814. E-mail: ivanacharousova@gmail.com
}

The actinomycines belong to a family of chromopeptide lactone antibiotics that present antitumor and cytotoxic properties (Praveen et al., 2008). They represent an important class of natural products that, despite being discovered more than 70 years ago, continue to be a focus of many research areas, especially in the biological and medicinal sciences (Kurosawa et al., 2006). Among the actinomycines, actinomycin D has been studied most extensively and it is used for treatment of malignant tumors, such as Wilms' tumor (Green, 1977), and childhood rhabdomyosarcoma (Womer, 1997). The biological activity of actinomycin $D$ is related to its ability to bind to the DNA duplex, these being associated with DNA functionality, leading to RNA and, consequently, protein synthesis inhibition (Martinez, Chacon-Garcia, 2005; Boer, Canals, Coll, 2009). The two main mechanisms are intercalation to DNA and the stabilization of cleavable complexes of topoisomerases I and II with DNA, or the drug penetrates to a place in the DNA structure where topoisomerase binds with DNA, 
respectively (Koba, Konopa, 2005). Actinomycin binds to the highest-energy beta-DNA form found within the boundaries connecting double-stranded B-DNA with single-stranded DNA in the transcription complex (Sobell, 2016) and physically obstructs the trascriptional complex (Huang et al., 2000).

Actinomycin D is produced by a range of Streptomyces species as part of a mixture of actinomycines (Kurosawa et al., 2006; Praveen et al., 2008).

Exploring new habitats is one of the most promising ways of isolating actinomycete producers of antibiotics endowed with antimicrobial activity (Zitouni et al., 2005; Khanna, Solanki, Lal, 2011; Wadetwar, Patil, 2013). Thus, we report here the antimicrobial activity of actinomycetes isolated from soil sample collected in Karoo, South Africa and characterization and identification of actinomycinproducing strain KRG-1.

\section{MATERIAL AND METHODS}

\section{Sample collection and processing}

Soil sample was collected from Aquilla Safari in the Southern Karoo, South Africa (332 21' 5.569'S; $19^{\circ} 56^{\prime} 8.23$ ”'E) from $10-15 \mathrm{~cm}$ depth and passed through a $2 \mathrm{~mm}$ sieve to remove debris and plants, in July 2015. Then the sample was dried for $45 \mathrm{~min}$ at $60{ }^{\circ} \mathrm{C}$ to eliminate the bacterial and fungal growth and stored in $4{ }^{\circ} \mathrm{C}$ until examination.

\section{Isolation of actinomycetes and maintenance}

Isolation and enumeration of actinomycetes were performed by the serial dilution method $\left(10^{-2}-10^{4}\right)$ and the spread plate technique on starch-casein medium (Poosarla, Ramana, Krishna, 2013) supplemented with cycloheximide $(1 \mathrm{mg} / \mathrm{mL})$. The plates were incubated at $30{ }^{\circ} \mathrm{C}$ for 7 days. Powdered colonies were picked up, transferred to ISP2 medium (Shirling, Gottlieb, 1966) and several times purified. Morphologically different isolates were named as KRG-1 - KRG-35 and stored in presence of $30 \%(\mathrm{v} / \mathrm{v})$ glycerol at $-20{ }^{\circ} \mathrm{C}$.

\section{Preliminary screening of actinomycetes for antimicrobial activity by agar plug method}

The actinomycete isolates were tested against eleven test microorganisms i.e. Bacillus subtilis (DSM 10), Micrococcus luteus (DSM1790), Staphylococcus aureus (Newman), Mycobacterium smegmatis (ATCC 700084), Escherichia coli (DSM 1116), Escherichia coli (TolC),
Pseudomonas aeruginosa (PA14), Chromobacterium violaceum (DSM 30191), Candida albicans (DSM 1665), Pichia anomala (DSM 6766)] and Mucor hiemalis (DSM 2656) obtained from the German Collection of Microorganisms and Cell Cultures, Braunschweig, Germany and the American Type Culture Collection, Manassas, VA 20110, USA. Primary screening for antibiotic activity of the isolates was done by using the agar plug method (Eccleston, Brooks, Kurtböke, 2008). Determination of activity was carried out by preparing 4-6 $\mathrm{h}$ cultures of tested bacteria followed by dilution with Mueller- Hinton (MH) broth (Merck, Germany) to obtain $0.05 \mathrm{McF}$ arland standard turbidity and 4-6 h culture of yeasts diluted with Mycosel broth (Cazin, Wiemer, Howard, 1989) to obtain 0.01 McFarland turbidity. Spores of Mucor hiemalis were collected in sterile distilled water and then adjusted to a spore density of approximately $10^{4}$ spores $/ \mathrm{mL}$. Plates were incubated at $30{ }^{\circ} \mathrm{C}$ and the zones of inhibition were determined after $24 \mathrm{~h}$ (bacteria and yeasts) and after $48 \mathrm{~h}$ (fungus) with the Haloes Caliper (IUL Instruments, USA).

\section{Extraction of antimicrobial compounds and secondary screening}

The selected antagonistic actinomycete isolates were inoculated into liquid 5254 medium (glucose: $15.0 \mathrm{~g} / \mathrm{L}$, soymeal: $15.0 \mathrm{~g} / \mathrm{L}$, corn steep: $5.0 \mathrm{~g} / \mathrm{L}, \mathrm{CaCO}_{3}: 2.0 \mathrm{~g} / \mathrm{L}$, $\mathrm{NaCl}: 5.0 \mathrm{~g} / \mathrm{L}$, deionized water: $1000 \mathrm{~mL}, \mathrm{pH}$ 7) supporting metabolite production and incubated at $30^{\circ} \mathrm{C}$ in a shaker at $250 \mathrm{rpm}$ for five days. After incubation period, the broths were mixed with ethyl acetate (Sigma Aldrich, USA) in ratio $1: 1$ and centrifuged $10 \mathrm{~min}$ at $9000 \mathrm{rpm}$. Supernatants were transferred to bottom flasks and evaporated in rotary evaporator (Stuart, UK) at $40^{\circ} \mathrm{C}$. Finally, the extracts were dissolved in $1 \mathrm{~mL}$ of ethylacetate:acetone:methanol $(1: 1: 1)$ solution, resulting in raw extracts of $1: 100$ concentration. The antimicrobial activities of those extracts were tested using the broth-microdillution method according to Wiegand, Hilpert, Hancock (2008) methodology against the same test microorganisms in 96-well microplates (BRAND, Germany). Dilution stages of raw extracts were determined by inhibited wells (A-H).

\section{Taxonomy and characterization of the most potent strain KRG-1}

The morphological, cultural, physiological and biochemical characterization as well as molecular and protein spectra identification of the isolate was carried out. 


\section{Morphological characteristics}

Morphological signs were examined according to methods given by the International Streptomyces Project (ISP) (Shirling, Gottlieb, 1966). ISP2-ISP7 media were used to determine the speed growth, reverse colors, colors of aerial mycelium and colors of soluble pigments. Melanin pigment production was determined on ISP6 and ISP7 media. For the light microscopic classification of the strain sporophores, well -grown agar plate with GYM (Větrovský, Steffen, Baldrian, 2014) medium was used.

\section{Physiological tests}

The physiological characteristics included $\mathrm{pH}$ tolerance ( $\mathrm{pH} 2-10)$ and determination of optimal temperature $\left(4,25,28,30,37\right.$ and $\left.42{ }^{\circ} \mathrm{C}\right)$ in liquid ISP2 medium. Sodium chloride tolerance $(0 ; 2.5 ; 5 ; 7.5$ and $10 \%$ ) was tested using six-well microtiter plates (Kutzner, 1981). Carbon utilization test (Shirling, Gottlieb, 1966) was done with 10 different carbon sources (glucose, arabinose, inositol, cellulose, mannose, fructose, galactose, rhamnose, sucrose, xylose) using twelve well microplate technique. The morphological and physiological characteristics of the strain were compared with the four phylogenetically most related species.

\section{Biochemical characteristics}

Biochemical features were examined using commercially available test kits ApiZym ${ }^{\circledR}$ and ApiCoryne ${ }^{\circledR}$ (bioMérieux, France). Api stripes were inoculated following by manufacturer's manual. Stripes were incubated for 1 day at $30^{\circ} \mathrm{C}$. After incubation period, reagents were added to cupules. After 5-10 min the stripes were evaluated according to the manual criteria.

\section{Molecular identification}

Molecular identification included extraction of the genomic DNA, PCR reaction and sequencing of 16S rRNA gene. Genomic DNA was extracted according to Deininger (1990) methodology. The isolated DNA was amplified by PCR reaction using primers according to Cook, Meyers (2003). Reaction mixture was made in total volume of $50 \mu \mathrm{L}$. Each reaction contained $5 \mu \mathrm{L}$ of $10 \times$ DreamTaq Green PCR buffer, $5 \mu \mathrm{L}$ of 2 mmol.dm ${ }^{-3} \mathrm{dNTP}, 2 \mu \mathrm{L}$ of each $10 \mu \mathrm{mol} . \mathrm{dm}^{-3}$ primer, $0,3 \mu 1$ Taq DNA polymerase and $0,5 \mu \mathrm{L}$ of template DNA (approximately $20 \mathrm{ng}$ ). The PCR reaction ran in the thermo cycler Biometra T Personal under the following conditions: $95^{\circ} \mathrm{C}$ for $3 \mathrm{~min}, 40$ cycles of $95^{\circ} \mathrm{C}$ for $30 \mathrm{sec}, 56^{\circ} \mathrm{C}$ for $30 \mathrm{sec}, 72^{\circ} \mathrm{C}$ for $90 \mathrm{sec}$ and final extension at $72{ }^{\circ} \mathrm{C}$ for $10 \mathrm{~min}$. The purified PCR product was sequenced with the help of the MacroGen
Genomics, Korea. Gaps and unidentified base positions were edited using BioEdit (Hall, 1999).

\section{Phylogenetic analysis}

Phylogenetic analysis was performed using the Maximum-Likelihood method (Felsenstein, 1981) using PhyML (Guindon, Gascuel, 2003) with bootstrap values based on the 1000 replications.

\section{MALDI-TOF MS analysis}

For the MALDI-TOF MS identification, cellular proteins were extracted according to Loucif et al. (2014). Four extraction procedures were performed, and $1 \mu \mathrm{L}$ of each suspension was deposited on the MALDI-TOF steel target plate (Bruker Daltonics, Germany) in three replicates. The plate was allowed to dry at room temperature and then overlaid with $1 \mu \mathrm{L}$ of matrix solution containing $\alpha$-cyano-hydroxycinnamic acid (SigmaAldrich, USA). Raw spectra obtained by the MALDI-TOF MS LT Microflex (Bruker Daltonics, Germany) were measured in linear positive mode and controlled by flexAnalysis 3.4 (Bruker Daltonics, Germany) for maximal purity. Every controlled mass spectrum was transferred to the MALDI Biotyper OC 3.1. For the clustering of streptomyces species, a mean spectra projection (MSP) dendrogram was created from mass ranging from 2-20 kDa. Obtained spectra were observed by the flexAnalysis 3.4 software (Bruker Daltonics, Germany). Evaluation of peaks was done by centroid detection algorithm with a signal-tonoise threshold of 1 , a relative intensity threshold of $0 \%$, a minimum intensity threshold of 0 , a peak width of $0.2 \mathrm{~m} / \mathrm{z}$, a height of $80 \%$, a Tophat baseline substraction, smoothing with the Savitzky-Golay algorithm, a width of $0.2 \mathrm{~m} / \mathrm{z}$, and cycle of 1 .

\section{HPLC fractionation and LC/MS analysis of secondary metabolite produced by the KRG-1}

The most potent extract was fractionated by the HPLC technique (Agilent 1100 with an analytical column X-Bridge $3.5 \mu \mathrm{m}, 2.1 \times 100 \mathrm{~mm}$; Waters, Milford, USA) and eluted at $0.3 \mathrm{~mL} / \mathrm{min}$ flow rate. For the HPLC measurement and separations we used following buffers: A2: $950 \mathrm{~mL} \mathrm{H}_{2} \mathrm{O}, 50 \mathrm{~mL}$ acetonitrile $+0.05 \mathrm{mM}$ $(385 \mathrm{mg} / \mathrm{L})$ ammonium acetate $+40 \mu \mathrm{L}$ acetic acid; B2: $50 \mathrm{~mL} \mathrm{H}_{2} \mathrm{O}, 950 \mathrm{~mL}$ acetonitrile, $0.05 \mathrm{mM}(385 \mathrm{mg} / \mathrm{L})$ ammonium acetate $+40 \mu \mathrm{L}$ acetic acid and a DAD detector $(200-400 \mathrm{~nm})$. Each fraction with volume $0.15 \mathrm{~mL}$ from the HPLC column was collected in a 96-well plate every $0.5 \mathrm{~min}$. The fractions in the 96-well plate were dried for $60 \mathrm{~min}$ at $40{ }^{\circ} \mathrm{C}$ in MiniVap (Porvair Sciences, UK). 
Afterwards, each well of plate was filled with $150 \mu \mathrm{L}$ of the Staphylococcus aureus diluted with MH broth. After incubation time, the inhibited wells were visible, and therefore the extract was applied to LC-MS system [(Agilent 1200 series with DAD detector $(200-600 \mathrm{~nm})$ in connection with a maXis UHR-TOF mass spectrometer (Bruker Daltonics, USA)] for peak-activity correlation. Sample was analyzed using the Waters ACQUITY UPLC BEH C18 Column, 2.1 x 50 mm, $1.7 \mu \mathrm{m}$. Chromatographic conditions for $\mathrm{LC} / \mathrm{MS}$ analysis were set: column oven temperature $40{ }^{\circ} \mathrm{C}$, flow rate $0.6 \mathrm{~mL} / \mathrm{min}$, solvent $\mathrm{A}\left(\mathrm{H}_{2} \mathrm{O}\right.$ with $0.1 \%$ formic acid), solvent $\mathrm{B}\left(\mathrm{CH}_{3} \mathrm{CN}\right.$ with $0.1 \%$ formic acid), gradient profile $0.5 \mathrm{~min}, 5 \% \mathrm{~B}$; in $19.5 \mathrm{~min}$ to $95 \% \mathrm{~B}, 10 \mathrm{~min}, 95 \% \mathrm{~B}$ (maXis gradient). Equilibration time between samples was $5 \mathrm{~min}$. Active compound was identified with the "Data Analysis" software included in the Compass-software from Bruker (USA).

\section{RESULTS AND DISCUSSION}

\section{Antimicrobial activity of isolated actinomycetes}

Eighty-six actinomycete cultures were isolated from soil sample collected in Karoo, South Africa. Out of them thirty-four morphologically different isolates were subjected to primary screening using the agar plug method. The identical isolates were scored out. It was determined that out of 34 tested isolates, 21 produced inhibitory substances against at least one tested microorganism. According to the results, the inhibition zones against Gram-positive bacteria were larger and clearer compared to the Gram-negative bacteria, yeasts and fungus, indicating that these tested microorganisms were less susceptible to active substances produced by our isolates. Among the active isolates, 21 inhibited Gram-positive bacteria with inhibition zones ranging from $16-40 \mathrm{~mm}$ in the following order: Bacillus subtilis (21 isolates), Staphylococcus aureus (18 isolates), Micrococcus luteus (14 isolates) and Mycobacterium smegmatis (11 isolates). Eleven isolates inhibited Gramnegative bacteria, mostly Chromobacterium violaceum (11 isolates) and Escherichia coli (TolC) (7 isolates) with inhibition zones 12-20 mm. Growth of Pseudomonas aeruginosa and Escherichia coli (DSM1116) were suppressed by 2 strains with $12 \mathrm{~mm}$ inhibition zones. Ten active isolates were active against yeasts with 12-19 mm inhibition zones and only five strains suppressed the growth (12-14 mm) of Mucor hiemalis.

Our results support previous studies with previous studies, which showed that the most isolated Streptomyces spp. had activity against Gram-positive bacteria (Thakur et al., 2007; Euanorasetr et al., 2010). The study of Baskaran, Vijayakumar, Mohan (2011) also reported the highest antagonistic activities against Staphylococcus aureus and Bacillus subtilis. Another investigation revealed the antimicrobial activity of actinomycetes active against Staphylococcus aureus, Staphylococcus epidermidis, Escherichia coli and Pseudomonas vulgaris, with no effect against Pseudomonas aeruginosa and Candida albicans (Dalin et al., 2010).

The potential actinobacteria were selected based on the results of preliminary screening. The inhibition potential discovered during the primary screening was different from secondary screening. During the tests, it was found out that $40 \%$ of the strains had lost their inhibition potential. According to Robinson, Singh, Nigam (2001) there are two explanations for this. Firstly, the cultivation on solid and liquid media may lead to the production of different active secondary metabolites. Secondly, some compounds may be lost during the organic solvent extraction method, because active components may become inactivated during the extraction step.

One strain, namely KRG-1, exhibited a broad inhibitory effect against bacterial and fungal pathogens, and therefore was selected as the potent strain and used for identification and fermentation process.

\section{Taxonomic identification of the most active strain KRG-1}

The isolate was taxonomically characterized based on the morphological and physiological signs, genotypic data, phylogenetic analysis and analysis of protein spectra. Strain KRG-1 was a Gram-positive soil bacterium. Morphological examination of the 7 day-old culture revealed that both aerial and substrate mycelium were abundant. The aerial mycelium was well-developed and mature sporulating aerial mycelium was grey on majority of the tested media. The substrate mycelium was yellow. Diffusible yellow pigment was determined only on ISP2 medium and melanin was not produced. The detailed cultural and physiological characteristics and comparative analysis with the four most related strains are summarized in Table I.

Strain KRG-1 utilized glucose, inositol, fructose and rhamnose, moderate growth was determined in presence of xylose and mannose. This utilization was different from the patterns of all strains used for comparison, except for Streptomyces antibioticus. Growth of strain KRG-1 was observed at a wide range of temperature $\left(25-37^{\circ} \mathrm{C}\right)$, although the optimal temperature was at $28^{\circ} \mathrm{C}$. The initial $\mathrm{pH}$ range, for which growth was observed, was between $\mathrm{pH} 5-8$, while the optimal $\mathrm{pH}$ value was determined to 
Antimicrobial activity of actinomycetes and characterization of actinomycin-producing strain KRG-1 isolated from Karoo

TABLE I - Morphological and physiological characteristic of strain KRG-1 and phylogenetically related Streptomyces species

\begin{tabular}{|c|c|c|c|c|c|}
\hline \multirow{2}{*}{ Sign } & \multicolumn{5}{|c|}{ Streptomyces strain } \\
\hline & KRG-1 & 1 & 2 & 3 & 4 \\
\hline Spore chain & $\mathrm{RF}$ & $\mathrm{RF}$ & $\mathrm{RF}$ & SP & ND \\
\hline \multicolumn{6}{|c|}{ Aerial mass color } \\
\hline ISP2 & Umbra grey & Grey & Grey & Grey & Silk grey \\
\hline ISP3 & Umbra grey & Grey & Grey & Grey & Traffic grey \\
\hline ISP4 & Grey beige & Grey & Grey & Grey & Light ivory \\
\hline ISP5 & Yellow grey & Grey & Grey & Grey & Light ivory \\
\hline ISP6 & None & None & White & None & None \\
\hline ISP7 & Platinum grey & Grey & White & Grey & None \\
\hline \multicolumn{6}{|c|}{ Reverse side color } \\
\hline ISP2 & Maize yellow & Yellow & Red & Brown & Orange brown \\
\hline ISP3 & Honey yellow & Yellow & Red & Brown & Honey yellow \\
\hline ISP4 & Honey yellow & Yellow & Red & Brown & Ochre brown \\
\hline ISP5 & Honey yellow & Yellow & Black & Brown & Golden yellow \\
\hline ISP6 & Honey yellow & Yellow & Red & Brown & Green brown \\
\hline ISP7 & Sand yellow & Yellow & Red & Brown & Sand yellow \\
\hline Pigment & ISP2 honey yellow & None & ISP7 brown & ISP7 brown & ISP2,3,4,6, yellow \\
\hline Melanin & None & None & + & + & - \\
\hline \multicolumn{6}{|c|}{ Carbon source utilization } \\
\hline Glucose & + & + & + & + & + \\
\hline Arabinose & - & - & + & $(+)$ & + \\
\hline Sucrose & - & - & - & - & + \\
\hline xylose & $(+)$ & - & - & $(+)$ & + \\
\hline Inositol & + & + & - & - & + \\
\hline Mannose & $(+)$ & $(+)$ & - & $(+)$ & + \\
\hline Fructose & + & $(+)$ & $(+)$ & - & + \\
\hline Rhamnose & + & $(+)$ & $(+)$ & - & - \\
\hline Raffinose & - & - & - & - & + \\
\hline Cellulose & - & ND & - & - & + \\
\hline $\mathrm{NaCl}$ tolerance & 2.5 & ND & 5 & 5 & ND \\
\hline Temperature & 28 & 28 & 28 & 28 & 28 \\
\hline $\mathrm{pH}$ & $6-8$ & ND & ND & ND & ND \\
\hline
\end{tabular}

1 - Streptomyces antibioticus, 2 - Streptomyces griseoruber, 3 - Streptomyces longwooedensis, 4 - Streptomyces galbus, positive $(+)$ growth, negative $(-)$ growth, intermediate $((+))$ growth, ND - no data available

be 7. Strain KRG-1 was also capable of growth in the presence of $2.5 \% \mathrm{NaCl}$.

According to the Api Zym activity of the extracellular enzymes, we found out that isolate KRG-1 showed high (> 40 nmol) alkaline phosphatase, leucinearylamidase and acid phosphatase activity. Moderate activity was determined in case of esterase-lipase, naphtol-AS-BIphosphohydrolase and glucosidase. Contrary, the least occurring enzymes were lipase, trypsin, chymotrypsin, glucuronidase and fucosidase. These results are in line with findings of Vítezová (2013) who reported, that the most common enzymes detected in ApiZym stripes are alkaline phosphatase and valinearylamidase and glucuronidase was the least occurring. Other enzymes and fermentation tests were determined by the ApiCoryne ${ }^{\circledR}$ stripes. Isolate KRG-1 showed positive activity for nitrate reduction, 
alkaline phosphatase, $\beta$-galactosidase, $\alpha$-glucosidase and gelatine hydrolysis. Majority of streptomycete species showed positive activity for the mentioned activities (Khan et al., 2010; Sakiyama et al., 2014).

The nucleotide sequence of the 16S rRNA gene was determined on the both strands (1239 bp) and has been assigned to the GenBank under the accession number KX827270. Obtained sequence was subjected to similarity searches using the BLAST tool to deduce phylogenetic relationships of this strain. The phylogenetic tree (Figure 1) from representative and the most similar strains indicated that strain KRG-1 belongs to the genus Streptomyces. In the comparison of $16 \mathrm{~S}$ rRNA gene, KRG-1 was mostly related with Streptomyces antibioticus (99\% similarity) and Streptomyces griseoruber (99\% similarity). The MSP dendrogram (Figure 2) constructed using our local Streptomyces database spectra clustered the strain KRG-1with Streptomyces antibioticus. Scientific information from the literature highlights the fact that Streptomyces antibioticus is one of the most productive strains of antibiotics. Examples of secondary metabolites produced by this strain are given in Table II.

\section{Antimicrobial activity and compound identification of the most potent strain KRG-1}

During the secondary screening, the range of inhibited wells of the selected strain revealed, that the extract exhibited the strongest antimicrobial activity against Gram-positive bacterium Staphylococcus aureus (inhibited wells until H) (Table III) and therefore it was subjected to the HPLC fractionation against this bacterium.

Inhibited wells were visible at retention times 20.0-23.5 min, where active fractions were located and therefore the extract was applied to LC/MS system for identification of active substances.

Chromatographic analysis revealed that extract contained at least one active compound active against suppressed bacterium. The peak-activity-correlation of the LC/MS analysis revealed that the active fractions were located between retention times 13.67-13.94 min. The peak appearing at this retention times exhibited UV-VIS maxima at $442 \mathrm{~nm}$ and the ESI-HRMS spectrum showing the prominent ion clusters for $\left[\mathrm{M}-\mathrm{H}_{2} \mathrm{O}+\mathrm{H}\right]^{+}$at $m / z 635.3109$ and for $[\mathrm{M}+\mathrm{Na}]^{+}$at $m / z 1269.6148$ (figure 3). According to the available databases, this result could be assigned to actinomycin D. The actinomycines are chromopeptide lactones produced by various Streptomyces strains (Praveen et al., 2008). They consist of a phenoxazinone chromophore (actinocin) with two pentapeptide lactone rings attached in amide linkage (Sakiyama et al.,

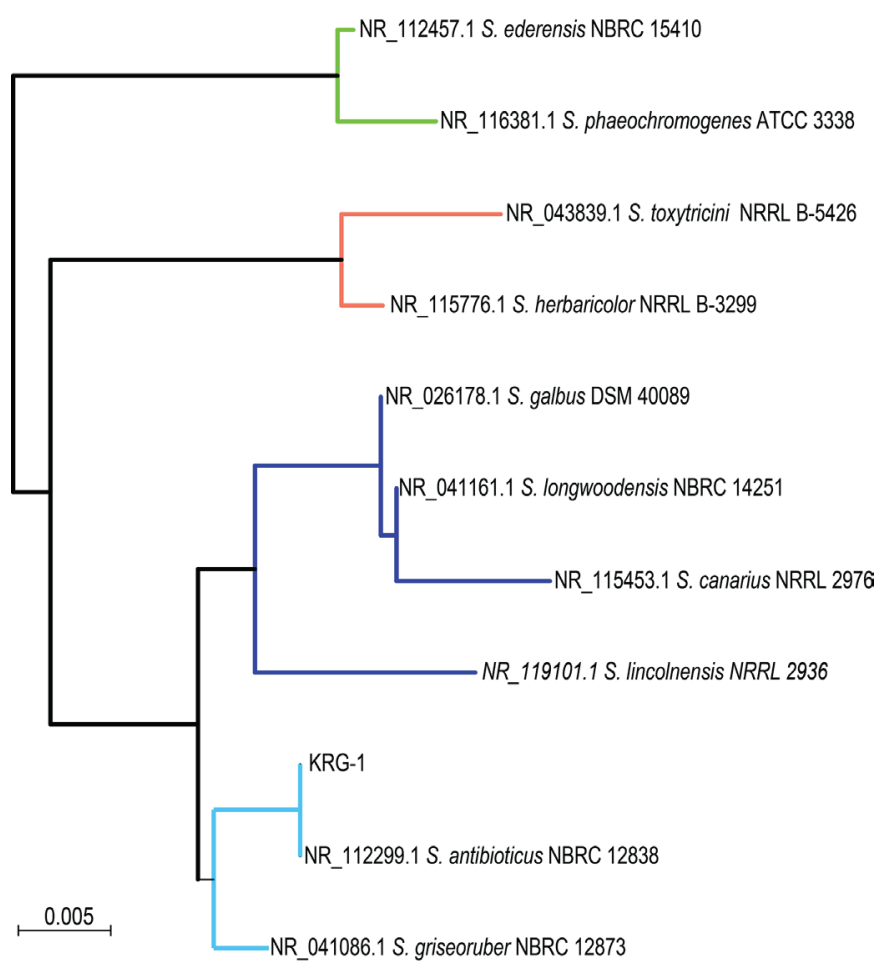

FIGURE 1 - Phylogenetic position of isolate KRG-1 and related Streptomyces species based on the 16S rRNA gene sequences.

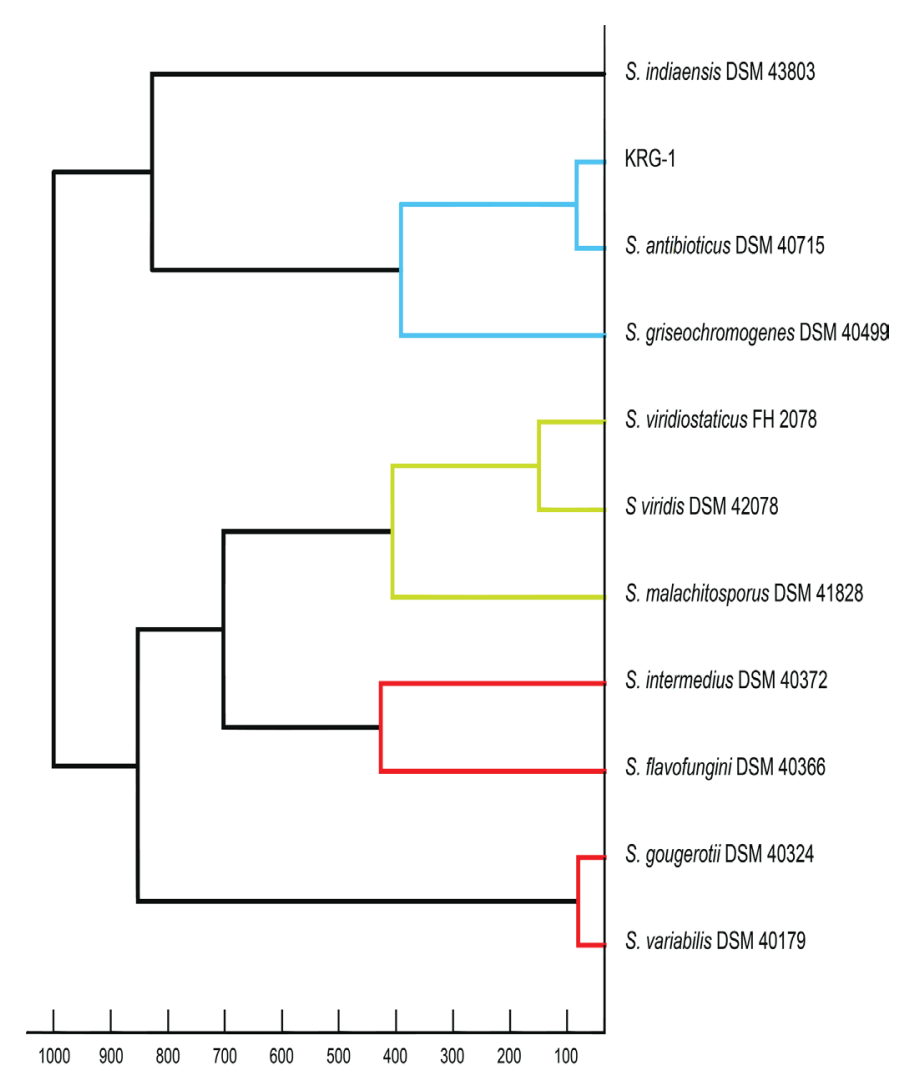

FIGURE 2 - MSP dendrogram of isolate KRG-1 based on the protein spectra with local Streptomyces database of type cultures. 
TABLE II - Chemical structure and mode of action of selected antibiotics produced by Streptomyces antibioticus

\begin{tabular}{lcc}
\hline Name of antibiotic & Chemical structure and mode of action & References \\
\hline Actinomycin & chromopeptid, antitumor activity & Jones, 2000 \\
Boromycin & polyether macrolide, antibacterial, coccidiosstat activity & Shibata et al., 1985 \\
Chlorothricin & macrolide, antibiotic activity & Waksman, Tishler, 1942 \\
Cinerubin & anthracycline, antibacterial, antiviral, antitumor activity & Hütter et al., 1967 \\
Esmeraldine A & diphenazine, antibacterial, antitumor activity & Keller-Schierlein et al., 1988 \\
Oleandomycin & macrolide, broad spectrum antibacterial agent & Semenitz, 1977 \\
Simocyclinones & angucyclinone, antitumor activity & Schimana et al., 2000 \\
Desferroferrithiocin & alkaloid & Naegeli, Zahner, 1980 \\
\hline
\end{tabular}

TABLE III - Antimicrobial activity of isolate KRG-1 in primary and secondary screening

\begin{tabular}{lcc}
\hline Indicator test microorganism & Primary screening (mm) & Secondary screening (A-H) \\
\hline Bacillus subtilis (DSM10) & 30 & $\mathrm{G}$ \\
Chromobacterium violaceum (DSM30191) & 16 & $\mathrm{C}$ \\
Escherichia coli (DSM116) & 12 & $\mathrm{~A}$ \\
Escherichia coli (TolC) & 16 & $\mathrm{~B}$ \\
Micrococcus luteus (DSM1790) & 20 & $\mathrm{~F}$ \\
Pseudomonas aeruginosa (PA14) & 12 & - \\
Mycobacterium smegmatis (ATC700084) & 16 & $\mathrm{D}$ \\
Staphylococcus aureus (Newman) & 35 & $\mathrm{H}$ \\
Mucor hiemalis (DSM2656) & 14 & $\mathrm{~A}$ \\
Pichia anomalia (DSM6766) & 12 & $\mathrm{~B}$ \\
Candida albicans (DSM1665) & 12 & - \\
\hline
\end{tabular}

Diameter of the inhibition zone using the agar plug method excluding the diameter of Streptomyces agar block ( $8 \mathrm{~mm})$

2014). Since the discovery of actinomycin D, it has become an important tool in molecular and cell biology (Kurosawa et al., 2006) because of its unique structure and biological properties by intercalating into duplex DNA, which results in inhibition of DNA-dependent RNA polymerase and thus protein synthesis (Mukhtar, Ijaz, Ul-Haq, 2012). To our knowledge, Streptomyces and Micromonospora species were reported capable of producing actinomycins (Kurosawa et al., 2006; Praveen, Tripathi, 2009). Antimycines were isolated for example from Streptomyces parvulus RSPSN2 (Keller et al., 2010), Streptomyces sindenensis (Praveen et al., 2008), Streptomyces avermitilis MS449 (Watkins et al., 1998), Streptomyces griseoruber (Shetty et al., 2014), Streptomyces nasri (Chen et al., 2012), Streptomyces chrysomallus (Sakiyama et al., 2014) and Streptomyces triostinicus (Praveen et al., 2009). There was a previous reports stating that also Streptomyces antibioticus produced actinomycin (El-Naggar, 1988; Singh et al.,
2009) - however, not from South Africa and different species reported by different research groups may be the same species due to a lack of standard strain and not enough information regarding the characteristics of each strain (Shirling, Gottlieb, 1966).

\section{CONCLUSION}

This manuscript deals with the isolation of streptomycetes from poorly studied aridic soil sample collected from South Africa - it is a bioassay activity against human pathogens, exact identification of actinomycin-producing streptomycete strain KRG-1 and it gives a clear idea that unexplored soils could be an interesting source for exploring antibacterial secondary metabolites. The search for the very effective actinomycines, and mainly actinomycin $\mathrm{D}$, requires the screening and the exact identification of many Streptomyces strains. The use of the MALDI-TOF MS 


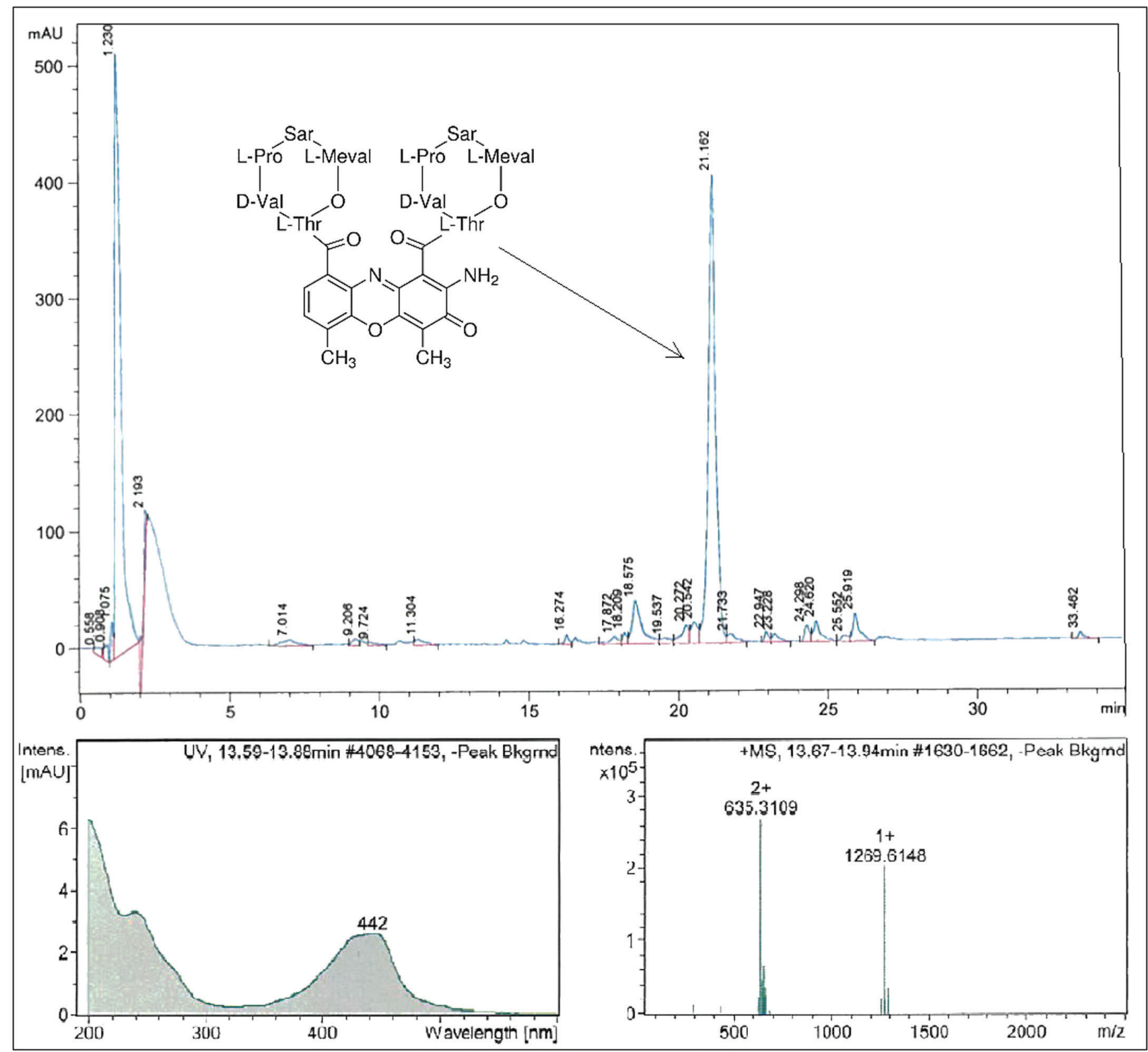

FIGURE 3 - Fractionation RP-HPLC chromatogram of detected antibiotic actinomycin D with UV spectrum and prominent ion clusters

has led to the rapid and powerful technique with a high accuracy for the more exact identification of the KRG-1 strain. This analysis together with the 16S rRNA sequence as well as morphological, physiological and biochemical features of the two most similar strains revealed that the active isolate was indeed to $\mathrm{S}$. antibioticus. The strain KRG-1 is a promising strain and can be used for the industrial applications.

\section{ACKNOWLEDGMENTS}

The author is grateful to the Helmholtz Centre for Infection Research (Microbial Strain Collection Group), Braunschweig, Germany, for the internship and for the support during obtaining the results. Special thanks to
PD Dr. Joachim Wink and Dipl.-Ing. Heinrich Steinmetz for the valuable help in working with actinomycetes and for excellent advice and discussions. This study was also supported by the Scientific Grant Agency of the Ministry of Education of the Slovak Republic and of the Slovak Academy of Sciences grant no. Vega 1/0305/17. The authors are grateful to Mrs. Martina Drexlerova for the English corrections.

\section{REFERENCES}

Baskaran R, Vijayakumar R, Mohan PM. Enrichment method for the isolation of bioactive actinomycetes from mangrove sediments of Andaman Islands, India. Mal J Microbiol. 2011;7(1):26-32. 
Bérdy J. Bioactive microbial metabolites. J Antibiot. 2005;58(1):1-26.

Boer DR, Canals A, Coll M. DNA-binding drugs caught in action: the latest 3D pictures of drug-DNA complexes. Dalton Trans. 2009;3:399-414.

Cazin J, Wiemer DF, Howard JJ. Isolation, growth characteristics, and long-term storage of fungi cultivated by attine ants. App Env Micro. 1989;55(6):1346-1350.

Ceylan O, Okmen G, Ugur A. Isolation of soil Streptomyces as source antibiotics active against antibiotic-resistant bacteria. Eur Asia J Bio Sci. 2008;2:73-82.

Chen C, Song F, Wang Q, Abdel-Mageed WM, Guo H, Fu C, et al. A marine-derived Streptomyces sp. MS449 produces high yield of actinomycin X2 and actinomycin D with potent anti-tuberculosis activity. App Microbiol Biotechnol. 2012;95(4):919-927.

Cook AE, Meyers PR. Rapid identification of filamentous actinomycetes to the genus level using genus-specific $16 \mathrm{~S}$ rRNA gene restriction fragment patterns. Int J Syst Evol Microbiol. 2003;53(Pt 6):1907-1915.

Dalin H, Guifeng Y, Yajuan X, Naixiang L, Jianhong C, Jiang lianxiu L, Senzhou C. Isolation and identification of Actinomycetes sp. BH0954 from the mangrove forest soil of Guangxi Beihai. Chin Agric Sci Bull. 2010;26:406-409.

Deininger P. A laboratory manual. In: Sambrook J, Fritsch EF, Maniatis T. Molecular cloning. NY: Cold Spring Harbor; 1990.

Eccleston GP, Brooks PR, Kurtböke DI. The occurrence of bioactive Micromonosporae in aquatic habitats of the sunshine coast in Australia. Mar Drugs. 2008;6(2):243-261.

El-Naggar MYM. Synergistic effect of actinomycin X2 produced by Streptomyces nasri YG62 with other antibiotics. Biomed Lett. 1988;58(230):169-173.

Euanorasetr J, Nilvongse A, Tantimavanich S, Nihira T, Igarashi $\mathrm{Y}$, Panbangred $\mathrm{W}$. Identification and characterization of soil-isolated Streptomyces SJE177 producing actinomycin. Southeast. Asian J Trop Med Public Health. 2010;41(5):11771187.

Felsenstein J. Evolutionary trees from DNA sequences: A maximum likelihood approach. J Mol Evol. 1981;17(6):368376.
Green DM. Paediatric oncology update/Wilms' tumour. Eur J Cancer. 1977;33(3):409-418.

Guindon S, Gascuel O. A simple, fast and accurate algorithm to estimate large phylogenies by maximum likelihood. Syst Biol. 2003;52(5):696-704.

Hall TA. BioEdit: a user-friendly biological sequence alignment editor and analysis program for Windows 95/98/NT. Nucleic Acids Symp Ser. 1999;41:95-98.

Huang P, Sandoval A, Van Den Neste E, Keating MJ, Plunkett W. Inhibition of RNA transcription: a biochemical mechanism of action against chronic lymphocytic leukemia cells by fludarabine. Leukemia. 2000;14(8):1405-1413.

Hütter R, Keller-Schien W, Knüsel F, Prelog V, Rodgers GC, Suter P, et al. Stoffwechselprodukte von Mikroorganismen. 57. Mitteilung. Boromycin. Helv Chim Acta. 1967;50(6):15331539.

Jones GH. Actinomycin production persists in a strain of Streptomyces antibioticus lacking phenoxazinone synthase. Antimicrob Agents Chem. 2000;44(5):1322-1327.

Kämpfer P. Genus Streptomyces: The Actinobacteria. In: Goodfellow M, Kämpfer P, Busse HJ, Trujillo, ME, Suzuki K, Ludwig W, Whitman WB (editors). Bergey's Manual of Systematic Bacteriology. New York: Springer; 2012. p.14551767.

Kekuda TRP, Shobha KS, Onkarappa R. Fascinating diversity and potent biological activities of actinomycete metabolites. J Pharm Res. 2010;3(2):250-256.

Keller U, Lang M, Crnovcic I, Pfennig F, Schauwecker F. The actinomycin biosystheti gene cluster of Streptomyces chrysomallus: a genetic hall of mirrors for synthesis of a molecule with mirror symmetry. J Bacteriol. 2010;192(10):2583-2595.

Keller-Schierlein W, Geiger A, Zähner H, Brandl M. Stoffwechselprodukte von Mikroorganismen. 251. Mitteilung. Die Esmeraldine A und B, tief grüne Farbstoffe aus Streptomyces antibioticus, Stamm Tü 2706. Helv Chim Acta. 1988;71(8):20582070.

Khan ST, Tamura T, Takagi M, Shinya K. Streptomyces tateyamensis sp. nov., Streptomyces marinus sp. Nov. and Streptomyces haliclonae sp. nov., isolated from the marine sponge Haliclona sp. J Sys Evol Microbiol. 2010;60(Pt 12):2775-2779. 
Khanna M, Solanki R, Lal R. Selective isolation of rare actinomycetes producing novel antimicrobial compounds. Int J Adv Biotechnol Res. 2011;2(3):357-375.

Koba M, Konopa J. [Actinomycin D and its mechanisms of action]. Postepy Hig Med Dosw. 2005;59:290-298.

Kurosawa KB, VanEssendelft JL, Willis LB, Lessard PA, Ghiviriga I, Sambandan TG, Rha CK, Sinskey AJ. Characterization of Streptomyces MITKK-103, a newly isolated actinomycin X2-producer. Appl Microbiol Biotechnol. 2006;72(1):145-154.

Kutzner HJ. The family Streptomycetaceae. In: Starr MP, Stolp H, Trüpper HG, Balons A, Schlegel HG (editors). The prokaryotes - A handbook on habitats, isolation and identification of bacteria. Berlin: Springer Verlag; 1981. p. 2028-2090.

Loucif L, Bendjama E, Gacemi-Kirane D, Rolain JM. Rapid identification of Streptomyces isolates by MALDI-TOF MS. Microbiol Res. 2014;169(12):940-947.

Martinez R, Chacon-Garcia L. The search of DNA-intercalators as antitumoral drugs: what it worked and what did not work. Curr Med Chem. 2005;12(2):127-151.

Meena B, Rajan LA, Vinithkumar NV, Kirubagaran R. Novel marine actinobacteria from emerald Andaman \& Nicobar Islands: a prospective source for industrial and pharmaceutical by products. BMC Microbiol. 2013;13:145-161.

Mukhtar H, Ijaz S, Ul-Haq I. Production of antitumor antibiotic by Streptomyces capoamus. Pak J Bot. 2012;44(1):445-452.

Naegeli HU, Zahner H. Metabolites of microorganisms: Ferrithiocin. Helv Chim Acta. 1980;63:1400-1406.

Poosarla A, Ramana V, Krishna RM. Isolation of potent antibiotic producing actinomycetes from marine sediments of Andaman and Nicobar marine islands. J Microbiol Antimicrob. 2013;5:6-12.

Praveen V, Tripathi C. Studies on the production of actinomycin-D by Streptomyces griseoruber - a novel source. Lett App Microbiol. 2009;49(4):450-455.

Praveen V, Tripathi CKM, Bihari V, Srivastava SC. Production of actinomycin-D by the mutant of a new isolate of Streptomyces sindenensis. Braz J Microbiol. 2008;39(4):689-692.
Robinson T, Singh D, Nigam P. Solid state fermentation: a promising microbial technology for secondary metabolite production. Appl Microbiol Biotechnol. 2001;55(3):284-289.

Sakiyama Y, Giang NM, Miyadoh S, Luong DT, Hop DV, Ando K. Streptomyces catbensis sp. nov., isolated from soil. J Sys Evol Microbiol. 2014;64(Pt 6):2146-2151.

Schimana J, Fiedler HP, Groth I, Sussmuth R, Beil W, Walker M, Zeeck A. Simocyclinones, novel cytostatic angucyclinone antibiotics produced by Streptomyces antibioticus Tü 6040. I. Taxonomy, fermentation, isolation and biological activities. J Antibiot. 2000;53(8):779-787.

Semenitz E. The antibacterial activity of oleandomycin and erythromycin - a comparative investigation using microcalorimetry and MIC determination. J Antimicrob Chemother. 1977;4(5):455-457.

Shetty PR, Buddana SK, Tatipamula VB, Naga YVV, Ahmad J. Production of polypeptide antibiotic from Streptomyces parvulus and its antibacterial activity. Braz J Microbiol. 2014;45(1):303-312.

Shibata M, Uyeda M, Kido Y, Fujimoto Y, Takano Y, Yoshioka Y. Production of acidic actinomycin congeners by a mutant strain of Streptomyces antibioticus, No. B-1625. Agric Biol Chem. 1985;49(12):3377-3382.

Shirling ET, Gottlieb D. Methods for characterization of Streptomyces species. Int J System Evol Microbiol. 1966;16(3):313-340.

Singh V, Khan M, Khan S, Tripathi CKM. Optimization of actinomycin $\mathrm{V}$ production by Streptomyces triostinicus using artificial neural network and genetic algorithm. App Microbiol Biotechnol. 2009;82(2):379-385.

Sobell HM. Premeltons in DNA. J Struct Funct Genomics. 2016;17(1):17-31.

Takahashi Y. Exploitation of new microbial resources for bioactive compounds and discovery of new actinomycetes. Actinomycetology. 2004;18(2):54-61.

Thakur D, Yadav A, Gogoi BK, Bora TC. Isolation and screening of Streptomyces in soil of protected forest areas from the states of Assam and Tripura, India, for antimicrobial metabolites. J Med Mycol. 2007;17(4):242-249. 
Větrovský T, Steffen KT, Baldrian P. Potential of cometabolic transformation of polysaccharides and lignin in lignocellulose by soil Actinobacteria. PloS One. 2014;9(2):e89108.

Vítezová M. Characterisation of actinomycetes community from the heavy metals-pollute soil. Acta Univ Agri et Silvi Mende Brun. 2013;61(5):1471-1478.

Wadetwar RN, Patil AT. Isolation and characterization of bioactive actinomycetes from soil in and around Nagpur. Int J Pharm Sci Res. 2013;4(4):1428-1433.

Waksman SA, Tishler M. The chemical nature of actinomycin, an antimicrobial substance produced by Actinomyces antibioticus. J Biol Chem. 1942;142:277-286.

Watkins NJ, Gottschalk A, Neubauer G, Kastner B, Fabrizio P, Mann M, Luhrmann R. Cbf5p, a potential pseudouridine synthase, and Nhp2p, a putative RNA-binding protein, are present together with Garlp in all H BOX/ACA-motif snoRNPs and constitute a common bipartite structure. RNA. 1998;4(12):1549-1568.
Wiegand I, Hilpert K, Hancock RE. Agar and broth dilution methods to determine the minimal inhibitory concentration (MIC) of antimicrobial substances. Nat Protoc. 2008;3(2):163175.

Womer RB. Soft tissue sarcomas. Eur J Cancer. 1997;33:22302234.

Zitouni A, Boudjella H, Lamari L, Badji B, Mathieu F, Lebrihi A, Sabaou N. Nocardiopsis and Saccharothrix genera in Saharan soils in Algeria: Isolation, biological activities and partial characterization of antibiotics. Res Microbiol. 2005;156(10):984-993.

Received for publication on $30^{\text {th }}$ September 2017 Accepted for publication on $21^{\text {st }}$ June 2018 